\title{
Variabilidade genética e ecológica de Stylosanthes macrocephala determinadas por RAPD e SIG
}

\author{
Ana Maria Barros ${ }^{(1)}$, Fábio Gelape Faleiro( ${ }^{(1)}$, Cláudio Takao Karia( ${ }^{(1)}$, Luciano Shozo Shiratsuchi(1), \\ Ronaldo Pereira de Andrade ${ }^{(1)}$ e George Kihoma Britto Lopes ${ }^{(1)}$
}

${ }^{(1)}$ Embrapa Cerrados, Caixa Postal 08223, CEP 73301-970 Planaltina, DF. E-mail: abarros@cpac.embrapa.br, ffaleiro@cpac.embrapa.br, karia@cpac.embrapa.br, shozo@cpac.embrapa.br, ronaldo@cpac.embrapa.br

\begin{abstract}
Resumo - Stylosanthes macrocephala M. B. Ferr. et S. Costa é uma leguminosa utilizada sob consorciação em pastagens, adubação e recuperação de áreas degradadas. A falta de características morfológicas e agronômicas estáveis e de informações ecogeográficas dos locais de coleta dos acessos tem dificultado o melhoramento genético da espécie. A fim de obter descritores ecológicos, moleculares e avaliar a variabilidade genética da coleção de S. macrocephala, 87 acessos foram analisados com o auxílio do Sistema de Informações Geográficas (SIG) e de marcadores moleculares RAPD. Os acessos provieram de sete Estados, cinco bacias hidrográficas, sete tipos de vegetação e sete tipos de solos. As altitudes dos locais de coleta variaram de 1 a $1.298 \mathrm{~m}$ e a pluviometria anual média de 550 a $2.870 \mathrm{~mm}$. A variabilidade de descritores ecológicos sugeriu diversidade adaptativa na coleção. Com base em 161 marcadores RAPD, verificou-se que as distâncias genéticas entre os acessos de $S$. macrocephala variaram entre 0,02 e 0,42. Com base nessas distâncias, dez grupos de similaridade genética foram estabelecidos. Observou-se tendência de separação por bacias hidrográficas e elevada variabilidade genética entre os acessos coletados nos estados da Bahia e de Minas Gerais. A alta variabilidade genética da coleção de $S$. macrocephala evidencia a importância desses acessos para futuros trabalhos de melhoramento genético.
\end{abstract}

Termos para indexação: diversidade genética, marcadores moleculares, germoplasma, leguminosa forrageira, Sistema de Informação Geográfica.

\section{Genetic and ecological variability of Stylosanthes macrocephala determined by RAPD markers and GIS}

\begin{abstract}
Stylosanthes macrocephala M. B. Ferr et S. Costa is a leguminous species used as forage, cover crop and as a pioneer plant to recover degraded areas. Inexistence of stable morphological descriptors and lack of ecogeographic information about collecting sites bring difficulties to the studies of this species. The objective of this work was to use the geographic information system (GIS) and RAPD markers to obtain ecological and molecular descriptors and to study the genetic variability of 87 S. macrocephala accessions. The accessions were collected from different ecogeographical areas in seven Brazilian States, five hydrographic regions, seven vegetation types and seven soil types. Collecting sites ranged from 1 to $1,298 \mathrm{~m}$ above sea level with annual rainfall from 550 to 2,870 $\mathrm{mm}$. Accession distribution along those diverse ecosystems indicate high adaptive diversity. Using 161 RAPD markers, genetic distances between accessions ranged from 0.02 to 0.42 . These genetic distances allowed the establishment of ten genetic groups. Accessions collected in specific hydrographic region tended to be grouped in the same genetic group. Accessions collected in Bahia and Minas Gerais States showed high genetic variability. The high genetic variability observed in the accessions showed the importance of this $S$. macrocephala collection for breeding programs.
\end{abstract}

Index terms: genetic diversity, molecular markers, germplasm, leguminous forage, geographic information system.

\section{Introdução}

O gênero Stylosanthes, pertencente à família Fabaceae, inclui 40 espécies e um grande número de subespécies e de variedades botânicas descritas (Ferreira \& Costa, 1979; Stace \& Edye, 1984). É originário da
América Central e do Sul, mas, em virtude de sua importância econômica, é encontrado sob cultivo também na América Subtropical e na Austrália (Stace \& Edye, 1984). A maioria das espécies é perene, com potente sistema radicular, tolerante à seca e de grande capacidade colonizadora por sua adaptação a solos de baixa 
fertilidade e simbiose com bactérias fixadoras de nitrogênio (Andrade \& Karia, 2000). Seu porte é prostrado a ereto, podendo alcançar até $1,5 \mathrm{~m}$, apresenta folhas trifolioladas, flores pequenas e caracteriza-se pela grande diversidade morfológica e agronômica (Ferreira \& Costa, 1979; Schultze-Kraft et al., 1984; Stace \& Edye, 1984). A maioria das espécies desse gênero é diplóide com $2 n=20$ cromossomos (Stace \& Edye, 1984), entretanto, algumas são alotetraplóides, como $S$. scabra e S. hamata (Stace \& Edye, 1984). O sistema de reprodução ocorre preferencialmente por autofecundação, com taxa de polinização cruzada da ordem de $2 \%$ a $6 \%$ em condições naturais (Stace, 1984; Miles, 1985).

Vários países têm empregado espécies do gênero Stylosanthes em pastagens em virtude da alta produção de massa verde e alto valor nutricional (Stace \& Edye, 1984). Esta utilização, apesar de vantajosa, tem sido pouco adotada no Brasil por falta de variedades com características que facilitem sua ampla utilização, como a baixa produção de sementes e a baixa persistência no campo que afetam o preço de mercado das sementes e adequação aos sistemas de produção existentes (Andrade \& Karia, 2000). Por meio de melhoramento genético, que utilize a variabilidade disponível nos bancos de germoplasma, tais limitações poderão ser solucionadas.

Os bancos de germoplasma têm por objetivo conservar material genético representativo da variabilidade genética da espécie e disponibilizar estes materiais para os programas de melhoramento (International..., 1996). Atualmente, a Embrapa Cerrados possui um banco com mais de 1.400 acessos do gênero Stylosanthes, sendo 136 S. macrocephala, com alto potencial em programas de melhoramento genético, conforme avaliações realizadas na Embrapa Cerrados (Andrade et al., 2004). A caracterização genética dos acessos é essencial para determinar o grau de variabilidade das coleções, enquanto características ecogeográficas dos pontos de coleta permitem inferir possíveis vantagens adaptativas de cada acesso (Chapman \& Barreto, 1996; Greene et al., 1999; Guarino et al., 2002). Ambas as informações orientam os programas de coleta e fornecem subsídios para a seleção do material adequado ao trabalho de melhoramento genético (Jarvis et al., 2003).

Atualmente, marcadores moleculares e o Sistema de Informação Geográfica (SIG) têm contribuído na caracterização dos acessos e no estudo da variabilidade genética, principalmente quando existe carência de descritores botânicos e agronômicos estáveis (Ferreira \& Grattapaglia, 1996; Harrison et al., 2000; Bertozo \& Valls, 2001).

O objetivo deste trabalho foi complementar e atualizar os dados sobre os locais de coleta de 87 acessos de Stylosanthes macrocephala, gerando descritores ecológicos para cada acesso, utilizando-se o Sistema de Informação Geográfica, e avaliar a variabilidade genética entre os acessos com base em marcadores RAPD (DNA polimórfico amplificado ao acaso).

\section{Material e Métodos}

Foram analisados 87 acessos de Stylosanthes macrocephala que apresentavam em seus passaportes informações sobre as coordenadas geográficas e os municípios dos pontos de coletas (Tabela 1). Estes acessos foram coletados em diferentes regiões do Brasil no período de 1975 a 1983, e fazem parte da coleção de 136 acessos de S. macrocephala do banco de germoplasma da Embrapa Cerrados. As sementes utilizadas são oriundas da primeira geração após a coleta e, em alguns casos, da segunda ou terceira geração. Como controle interespecífico (out group) foi utilizada a cultivar Mineirão, que pertence à espécie $S$. guianensis var. vulgaris (Embrapa, 1993).

Com o auxílio do programa ArcView versão 3.1 (ESRI, 1996), as coordenadas geográficas (latitude e longitude) do local de coleta de cada acesso foram plotadas conjuntamente em diferentes mapas do SIG (Brasil, 1981) com informações na escala de 1:1.000.000. Os mapas utilizados para obtenção dos descritores ecológicos de cada acesso foram: tipo de vegetação, tipo de solos, estados e municípios, bacias hidrográficas e pluviometria.

Com o objetivo de determinar a similaridade entre os ecossistemas dos pontos de coleta, realizou-se uma análise dos descritores ecológicos de cada acesso considerando as características de solo, vegetação, altitude e pluviometria. Foram classificados como "ambientes semelhantes" aqueles locais que compartilharam pelo menos 3 dos 4 descritores utilizados.

Folhas de cada acesso, em estádio intermediário de maturação, foram coletadas e utilizadas para a extração do DNA genômico utilizando-se o método do CTAB com algumas modificações (Faleiro et al., 2003). Para estudar a variabilidade genética entre plantas do mes- 
Tabela1. Acessos de Stylosanthes macrocephala da coleção da Embrapa Cerrados com as respectivas coordenadas geográficas e descritores ecológicos, genético e de similaridade ambiental ${ }^{(1)}$.

\begin{tabular}{|c|c|c|c|c|c|c|c|c|c|c|c|c|c|}
\hline \multirow[t]{2}{*}{ CPAC } & \multirow[t]{2}{*}{ Lat } & \multirow[t]{2}{*}{ Long } & \multirow[t]{2}{*}{ Data da coleta } & \multicolumn{2}{|c|}{ Local de coleta } & \multirow[t]{2}{*}{$\mathrm{E}$} & \multirow[t]{2}{*}{ B } & \multirow[t]{2}{*}{ A } & \multirow[t]{2}{*}{$\mathrm{S}$} & \multirow[t]{2}{*}{$\mathrm{P}$} & \multirow[t]{2}{*}{$\mathrm{V}$} & \multirow[t]{2}{*}{$\mathrm{G}$} & \multirow[t]{2}{*}{$\mathrm{C}$} \\
\hline & & & & Passaporte & SIG & & & & & & & & \\
\hline $1031^{(2)}$ & $14^{\circ} 52^{\prime} \mathrm{S}$ & $46^{\circ} 24^{\prime} \mathrm{W}$ & $27 / 09 / 78$ & Alvorada do Norte, GO & Formoso, MG & 4 & 5 & 5 & 3 & 6 & 6 & 2 & 38 \\
\hline $1032^{(2)}$ & $14^{\circ} 35^{\prime} \mathrm{S}$ & $46^{\circ} 9^{\prime} \mathrm{W}$ & $27 / 09 / 78$ & Alvorada do Norte, GO & Damianópolis, GO & 3 & 1 & 5 & 6 & 5 & 6 & 1 & 38 \\
\hline $1033^{(2)}$ & $12^{\circ} 14^{\prime} \mathrm{S}$ & $45^{\circ} 2^{\prime} \mathrm{W}$ & $06 / 10 / 78$ & Barreiras, BA & Barreiras, BA & 1 & 5 & 4 & 7 & 4 & 1 & 10 & 6 \\
\hline $1035^{(2)}$ & $12^{\circ} 7^{\prime} \mathrm{S}$ & $43^{\circ} 53^{\prime} \mathrm{W}$ & $28 / 09 / 78$ & Ibotirama, BA & Wanderley, BA & 1 & 5 & 5 & 7 & 3 & 4 & 3 & 28 \\
\hline $1036^{(2)}$ & $12^{\circ} 18^{\prime} \mathrm{S}$ & $42^{\circ} 54^{\prime} \mathrm{W}$ & $05 / 10 / 78$ & Ibotirama, BA & Oliveira dos Brejinhos, BA & 1 & 5 & 4 & 3 & 2 & 2 & 1 & 13 \\
\hline $1037^{(2)}$ & $12^{\circ} 21^{\prime} \mathrm{S}$ & $42^{\circ} 37^{\prime} \mathrm{W}$ & $29 / 09 / 78$ & Ibotirama, BA & Oliveira dos Brejinhos, BA & 1 & 5 & 4 & 3 & 1 & 2 & 1 & 10 \\
\hline $1039^{(2)}$ & $12^{\circ} 24^{\prime} \mathrm{S}$ & $41^{\circ} 52^{\prime} \mathrm{W}$ & $29 / 09 / 78$ & Seabra, BA & Seabra, BA & 1 & 2 & 7 & 3 & 2 & 1 & 1 & 4 \\
\hline $1040^{(2)}$ & $12^{\circ} 27^{\prime} \mathrm{S}$ & $41^{\circ} 39^{\prime} \mathrm{W}$ & $29 / 09 / 78$ & Seabra, BA & Seabra, BA & 1 & 2 & 5 & 3 & 3 & 6 & 1 & 33 \\
\hline $1041^{(2)}$ & $12^{\circ} 27^{\prime} \mathrm{S}$ & $41^{\circ} 38^{\prime} \mathrm{W}$ & $29 / 09 / 78$ & Seabra, BA & Seabra, BA & 1 & 2 & 5 & 3 & 3 & 6 & 9 & 33 \\
\hline $1043^{(2)}$ & $12^{\circ} 28^{\prime} \mathrm{S}$ & $41^{\circ} 17^{\prime} \mathrm{W}$ & $04 / 10 / 78$ & Seabra, BA & Lençóis, BA & 1 & 2 & 3 & 3 & 3 & 4 & 1 & 27 \\
\hline $1045^{(2)}$ & $12^{\circ} 33^{\prime} \mathrm{S}$ & $39^{\circ} 22^{\prime} \mathrm{W}$ & $30 / 09 / 78$ & Feira de Santana, BA & Rafael Jambeiro, BA & 1 & 2 & 1 & 1 & 2 & 4 & 1 & 24 \\
\hline $1187^{(2)}$ & $12^{\circ} 24^{\prime} \mathrm{S}$ & $41^{\circ} 52^{\prime} \mathrm{W}$ & $29 / 09 / 78$ & Seabra, BA & Seabra, BA & 1 & 2 & 7 & 3 & 2 & 1 & 1 & 4 \\
\hline $1190^{(2)}$ & $18^{\circ} 24^{\prime} \mathrm{S}$ & $43^{\circ} 33^{\prime} \mathrm{W}$ & $17 / 01 / 77$ & Diamantina, $\mathrm{MG}$ & Diamantina, $\mathrm{MG}$ & 4 & 2 & 6 & 7 & 4 & 6 & 3 & 36 \\
\hline $1191^{(2)}$ & $19^{\circ} 40^{\prime} \mathrm{S}$ & $43^{\circ} 55^{\prime} \mathrm{W}$ & $23 / 05 / 78$ & Lagoa Santa, MG & Lagoa Santa, MG & 4 & 5 & 6 & 3 & 6 & 1 & 3 & 9 \\
\hline $1192^{(2)}$ & $19^{\circ} 40^{\prime} \mathrm{S}$ & $43^{\circ} 55^{\prime} \mathrm{W}$ & $25 / 05 / 78$ & Lagoa Santa, MG & Lagoa Santa, MG & 4 & 5 & 6 & 3 & 6 & 1 & 8 & 9 \\
\hline $1193^{(2)}$ & $18^{\circ} 24^{\prime} \mathrm{S}$ & $44^{\circ} 39^{\prime} \mathrm{W}$ & $25 / 05 / 78$ & Datas, MG & Corinto, $\mathrm{MG}$ & 4 & 5 & 4 & 3 & 7 & 6 & 2 & 41 \\
\hline $1194^{(2)}$ & $18^{\circ} 24^{\prime} \mathrm{S}$ & $44^{\circ} 39^{\prime} \mathrm{W}$ & $26 / 05 / 78$ & Cruz Alta, MG & Corinto, $\mathrm{MG}$ & 4 & 5 & 4 & 3 & 7 & 6 & 1 & 41 \\
\hline $1196^{(2)}$ & $18^{\circ} 8^{\prime} \mathrm{S}$ & $43^{\circ} 33^{\prime} \mathrm{W}$ & $26 / 05 / 78$ & Diamantina, $\mathrm{MG}$ & Diamantina, $\mathrm{MG}$ & 4 & 2 & 6 & 7 & 4 & 6 & 2 & 36 \\
\hline $1197^{(2)}$ & $17^{\circ} 55^{\prime} \mathrm{S}$ & $43^{\circ} 4^{\prime} \mathrm{W}$ & $26 / 05 / 78$ & S. Modest. G., MG & Itamarandiba, $\mathrm{MG}$ & 4 & 2 & 6 & 3 & 4 & 3 & 1 & 20 \\
\hline $1198^{(2)}$ & $17^{\circ} 58^{\prime} \mathrm{S}$ & $43^{\circ} 10^{\prime} \mathrm{W}$ & $27 / 05 / 78$ & Felixberto C., MG & S. Modest. G., MG & 4 & 2 & 6 & 8 & 4 & 3 & 1 & 21 \\
\hline $1199^{(2)}$ & $17^{\circ} 11^{\prime} \mathrm{S}$ & $43^{\circ} 33^{\prime} \mathrm{W}$ & $07 / 06 / 79$ & Trebol, MG & Bocaiúva, MG & 4 & 2 & 6 & 7 & 3 & 6 & 4 & 34 \\
\hline $1200^{(2)}$ & $17^{\circ} 12^{\prime} \mathrm{S}$ & $43^{\circ} 26^{\prime} \mathrm{W}$ & $07 / 06 / 79$ & Diamantina, MG & Bocaiúva, MG & 4 & 2 & 6 & 7 & 3 & 6 & 1 & 34 \\
\hline $1201^{(2)}$ & $17^{\circ} 21^{\prime} \mathrm{S}$ & $42^{\circ} 41^{\prime} \mathrm{W}$ & $07 / 06 / 79$ & Turmalina, MG & Turmalina, MG & 4 & 2 & 5 & 8 & 4 & 1 & 1 & 7 \\
\hline $1202^{(2)}$ & $17^{\circ} 51^{\prime} \mathrm{S}$ & $43^{\circ} 22^{\prime} \mathrm{W}$ & $08 / 06 / 78$ & Sen. Mourão, MG & S. Modest. G., MG & 4 & 2 & 6 & 7 & 4 & 1 & 1 & 6 \\
\hline $1204^{(2)}$ & $18^{\circ} 8^{\prime} \mathrm{S}$ & $43^{\circ} 33^{\prime} \mathrm{W}$ & $08 / 06 / 79$ & Diamantina, MG & Diamantina, MG & 4 & 2 & 6 & 7 & 4 & 6 & 3 & 36 \\
\hline $1205^{(2)}$ & $18^{\circ} 8^{\prime} \mathrm{S}$ & $42^{\circ} 31^{\prime} \mathrm{W}$ & $08 / 06 / 79$ & Diamantina, $\mathrm{MG}$ & S. Sebast. Maranh., MG & 4 & 2 & 4 & 3 & 5 & 3 & 1 & 22 \\
\hline $1206^{(2)}$ & $17^{\circ} 6^{\prime} \mathrm{S}$ & $44^{\circ} 22^{\prime} \mathrm{W}$ & $07 / 08 / 79$ & Montes Claros, MG & Jequitaí, MG & 4 & 5 & 5 & 3 & 5 & 6 & 1 & 37 \\
\hline $1307^{(2)}$ & $16^{\circ} 7^{\prime} \mathrm{S}$ & $48^{\circ} 22^{\prime} \mathrm{W}$ & 03/10/80 & Brasília, DF & Alexânia, GO & 3 & 4 & 6 & 2 & 7 & 6 & 1 & 40 \\
\hline $1308^{(2)}$ & $14^{\circ} 30^{\prime} \mathrm{S}$ & $47^{\circ} 31^{\prime} \mathrm{W}$ & $15 / 10 / 80$ & S. João Aliança, GO & S. João Aliança, GO & 3 & 1 & 6 & 3 & 7 & 6 & 1 & 42 \\
\hline $1309^{(2)}$ & $15^{\circ} 48^{\prime} \mathrm{S}$ & $47^{\circ} 55^{\prime} \mathrm{W}$ & $02 / 10 / 80$ & Brasília, DF & Brasília, DF & 2 & 4 & 7 & 3 & 7 & 6 & 1 & 42 \\
\hline $1310^{(2)}$ & $15^{\circ} 43^{\prime} \mathrm{S}$ & $48^{\circ} 12^{\prime} \mathrm{W}$ & $02 / 10 / 80$ & Sto. Antônio D., DF & Brasília, DF & 2 & 4 & 7 & 2 & 7 & 6 & 1 & 40 \\
\hline 1311 & $14^{\circ} 59^{\prime} \mathrm{S}$ & $47^{\circ} 34^{\prime} \mathrm{W}$ & $15 / 10 / 80$ & S. João Aliança, GO & Formosa, GO & 3 & 1 & 7 & 3 & 7 & 6 & 1 & 42 \\
\hline 1332 & $13^{\circ} 49^{\prime} \mathrm{S}$ & $41^{\circ} 19^{\prime} \mathrm{W}$ & $24 / 08 / 81$ & Ituaçu, BA & Ituaçu, BA & 1 & 2 & 4 & 7 & 1 & 1 & 1 & 1 \\
\hline 1333 & $13^{\circ} 40^{\prime} \mathrm{S}$ & $41^{\circ} 25^{\prime} \mathrm{W}$ & $23 / 08 / 81$ & Mucujé, BA & Barra da Estiva, BA & 1 & 2 & 6 & 3 & 1 & 6 & 1 & 31 \\
\hline 1336 & $12^{\circ} 31^{\prime} \mathrm{S}$ & $41^{\circ} 22^{\prime} \mathrm{W}$ & $04 / 09 / 81$ & Itaberaba, BA & Lençóis, BA & 1 & 2 & 3 & 3 & 3 & 3 & 1 & 18 \\
\hline 1337 & $13^{\circ} 42^{\prime} \mathrm{S}$ & $40^{\circ} 58^{\prime} \mathrm{W}$ & $24 / 08 / 81$ & Contendas Sinc., BA & Barra da Estiva, BA & 1 & 2 & 3 & 7 & 1 & 2 & 1 & 12 \\
\hline 1339 & $14^{\circ} 49^{\prime} \mathrm{S}$ & $40^{\circ} 50^{\prime} \mathrm{W}$ & $26 / 08 / 81$ & Vit. da Conquista, BA & Vit. da Conquista, BA & 1 & 2 & 6 & 3 & 2 & 4 & 1 & 25 \\
\hline 1340 & $12^{\circ} 48^{\prime} \mathrm{S}$ & $41^{\circ} 18^{\prime} \mathrm{W}$ & $21 / 08 / 81$ & Andaraí, BA & Andaraí, BA & 1 & 2 & 3 & 3 & 4 & 3 & 1 & 20 \\
\hline 1341 & $13^{\circ} 48^{\prime} \mathrm{S}$ & $41^{\circ} 21^{\prime} \mathrm{W}$ & $24 / 08 / 81$ & Ituaçu, BA & Ituaçu, BA & 1 & 2 & 4 & 7 & 1 & 1 & 1 & 1 \\
\hline 1345 & $13^{\circ} 9^{\prime} \mathrm{S}$ & $41^{\circ} 49^{\prime} \mathrm{W}$ & $20 / 08 / 81$ & Boninal, BA & Piata, BA & 1 & 2 & 7 & 7 & 2 & 6 & 6 & 32 \\
\hline 1346 & $15^{\circ} 16^{\prime} \mathrm{S}$ & $41^{\circ} 6^{\prime} \mathrm{W}$ & $27 / 08 / 81$ & Vit. da Conquista, BA & Vit. da Conquista, BA & 1 & 2 & 6 & 3 & 2 & 4 & 1 & 25 \\
\hline 1347 & $13^{\circ} 35^{\prime} \mathrm{S}$ & $41^{\circ} 22^{\prime} \mathrm{W}$ & $23 / 08 / 81$ & Mucujé, BA & Barra da Estiva, BA & 1 & 2 & 7 & 8 & 2 & 6 & 1 & 32 \\
\hline $1348^{(3)}$ & $12^{\circ} 10^{\prime} \mathrm{S}$ & $44^{\circ} 53^{\prime} \mathrm{W}$ & $19 / 08 / 81$ & Barreiras, BA & Barreiras, BA & 1 & 5 & 5 & 3 & 4 & 4 & (3) & 29 \\
\hline 1358 & $12^{\circ} 24^{\prime} \mathrm{S}$ & $42^{\circ} 35^{\prime} \mathrm{W}$ & $20 / 08 / 81$ & Seabra, BA & Oliveira dos Brejinhos, BA & 1 & 5 & 3 & 3 & 1 & 2 & 1 & 10 \\
\hline 1361 & $12^{\circ} 5^{\prime} \mathrm{S}$ & $44^{\circ} 18^{\prime} \mathrm{W}$ & $19 / 08 / 81$ & Cristópolis, BA & Cotegipe, BA & 1 & 5 & 4 & 3 & 3 & 6 & 1 & 33 \\
\hline 1362 & $14^{\circ} 14^{\prime} \mathrm{S}$ & $40^{\circ} 19^{\prime} \mathrm{W}$ & $24 / 08 / 81$ & Jequié, BA & Manoel Vitorino, BA & 1 & 2 & 3 & 8 & 3 & 2 & 1 & 15 \\
\hline 1363 & $13^{\circ} 6^{\prime S}$ & $41^{\circ} 50^{\prime} \mathrm{W}$ & $20 / 08 / 81$ & Boninal, BA & Piata, BA & 1 & 2 & 6 & 7 & 3 & 6 & 1 & 34 \\
\hline 1367 & $14^{\circ} 5^{\prime} \mathrm{S}$ & $46^{\circ} 7^{\prime} \mathrm{W}$ & $18 / 08 / 81$ & Alvorada do Norte, GO & Jaborandi, BA & 1 & 5 & 6 & 3 & 5 & 6 & 1 & 37 \\
\hline 1373 & $12^{\circ} 30^{\prime} \mathrm{S}$ & $41^{\circ} 20^{\prime} \mathrm{W}$ & $21 / 08 / 81$ & Itaberaba, BA & Lençóis, BA & 1 & 2 & 3 & 3 & 3 & 3 & 1 & 18 \\
\hline 1376 & $12^{\circ} 27^{\prime} \mathrm{S}$ & $41^{\circ} 44^{\prime} \mathrm{W}$ & $22 / 08 / 81$ & Seabra, BA & Seabra, BA & 1 & 2 & 5 & 8 & 3 & 1 & 1 & 5 \\
\hline
\end{tabular}


Tabela 1. Continuação...

\begin{tabular}{|c|c|c|c|c|c|c|c|c|c|c|c|c|c|}
\hline \multirow[t]{2}{*}{ CPAC } & \multirow[t]{2}{*}{ Lat } & \multirow[t]{2}{*}{ Long } & \multirow[t]{2}{*}{ Data da coleta } & \multicolumn{2}{|c|}{ Local de coleta } & \multirow[t]{2}{*}{$\mathrm{E}$} & \multirow[t]{2}{*}{ B } & \multirow[t]{2}{*}{ A } & \multirow[t]{2}{*}{ S } & \multirow[t]{2}{*}{$\mathrm{P}$} & \multirow[t]{2}{*}{ V } & \multirow[t]{2}{*}{ G } & \multirow[t]{2}{*}{$\mathrm{C}$} \\
\hline & & & & Passaporte & SIG & & & & & & & & \\
\hline 1378 & $14^{\circ} 2^{\prime} \mathrm{S}$ & $41^{\circ} 6 \mathrm{~W}$ & $24 / 08 / 81$ & Contendas Sinc., BA & Tanhaçu, BA & 1 & 2 & 3 & 8 & 1 & 2 & 3 & 12 \\
\hline 1382 & $12^{\circ} 51^{\prime} \mathrm{S}$ & $41^{\circ} 50^{\prime} \mathrm{W}$ & $20 / 08 / 81$ & Boninal, BA & Piata, BA & 1 & 2 & 6 & 3 & 3 & 6 & 1 & 33 \\
\hline 1383 & $12^{\circ} 58^{\prime} \mathrm{S}$ & $41^{\circ} 51^{\prime} \mathrm{W}$ & $20 / 08 / 81$ & Boninal, BA & Piata, BA & 1 & 2 & 7 & 7 & 3 & 6 & 1 & 34 \\
\hline $1636^{(2)}$ & $1^{\circ} 26^{\prime} \mathrm{S}$ & $48^{\circ} 30^{\prime} \mathrm{W}$ & - & Belém, PA & Belém, PA & - & - & - & - & - & - & 1 & - \\
\hline 1639 & $12^{\circ} 25^{\prime} \mathrm{S}$ & $38^{\circ} 54^{\prime} \mathrm{W}$ & $18 / 07 / 80$ & Cruz das Almas, BA & S. Gonçalo Campos, BA & 1 & 2 & 1 & 8 & 5 & 1 & 1 & 8 \\
\hline 1640 & $12^{\circ} 14^{\prime} \mathrm{S}$ & $38^{\circ} 28^{\prime} \mathrm{W}$ & $18 / 07 / 80$ & Alagoinhas, BA & Alagoinhas, BA & 1 & 2 & 1 & 8 & 5 & 5 & 1 & 30 \\
\hline $1641^{(2)}$ & $14^{\circ} 33^{\prime} \mathrm{S}$ & $47^{\circ} 30^{\prime} \mathrm{W}$ & $01 / 05 / 75$ & Alto Paraíso, GO & S. João d'Aliança, GO & 3 & 1 & 6 & 2 & 7 & 6 & 1 & 40 \\
\hline $1642^{(2)}$ & $11^{\circ} 30^{\prime} \mathrm{S}$ & $49^{\circ} 0^{\prime} \mathrm{W}$ & $02 / 07 / 75$ & Duerê, GO & Duerê, TO & 7 & 1 & 2 & 3 & 9 & 6 & 1 & 44 \\
\hline $1644^{(2)}$ & $14^{\circ} 15^{\prime} \mathrm{S}$ & $49^{\circ} 20^{\prime} \mathrm{W}$ & $18 / 05 / 76$ & Hidrolândia, GO & Alto Horizonte, GO & 3 & 1 & 5 & 3 & 8 & 6 & 1 & 43 \\
\hline 2227 & $11^{\circ} 53^{\prime} \mathrm{S}$ & $38^{\circ} 4^{\prime} \mathrm{W}$ & $18 / 07 / 80$ & Alagoinhas, BA & Entre Rios, BA & 1 & 2 & 1 & 8 & 6 & 3 & 1 & 23 \\
\hline 2230 & $14^{\circ} 5^{\prime} \mathrm{S}$ & $46^{\circ} 7^{\prime} \mathrm{W}$ & $18 / 08 / 81$ & Alvorada do Norte, GO & Jaborandi, BA & 1 & 5 & 6 & 3 & 5 & 6 & 1 & 37 \\
\hline 2231 & $12^{\circ} 9^{\prime} \mathrm{S}$ & $45^{\circ} 1^{\prime} \mathrm{W}$ & $19 / 08 / 81$ & Barreiras, BA & Barreiras, BA & 1 & 5 & 3 & 7 & 4 & 1 & 1 & 6 \\
\hline 2232 & $12^{\circ} 10^{\prime} \mathrm{S}$ & $44^{\circ} 53^{\prime} \mathrm{W}$ & $19 / 08 / 81$ & Barreiras, BA & Barreiras, BA & 1 & 5 & 5 & 3 & 4 & 4 & 1 & 29 \\
\hline 2235 & $12^{\circ} 58^{\prime} \mathrm{S}$ & $41^{\circ} 51^{\prime} \mathrm{W}$ & $20 / 08 / 81$ & Boninal, BA & Piata, BA & 1 & 2 & 7 & 7 & 3 & 6 & 1 & 34 \\
\hline 2239 & $12^{\circ} 48^{\prime} \mathrm{S}$ & $41^{\circ} 18^{\prime} \mathrm{W}$ & $21 / 08 / 81$ & Andaraí, BA & Andaraí, BA & 1 & 2 & 3 & 3 & 4 & 3 & 1 & 20 \\
\hline 2251 & $15^{\circ} 53^{\prime} \mathrm{S}$ & $41^{\circ} 24^{\prime} \mathrm{W}$ & $27 / 08 / 81$ & Divisa Alegre, $\mathrm{MG}$ & Cachoeira do Pajeú, MG & 4 & 2 & 5 & 3 & 4 & 4 & 1 & 29 \\
\hline 2252 & $12^{\circ} 6^{\prime} \mathrm{S}$ & $39^{\circ} 57^{\prime} \mathrm{W}$ & $04 / 09 / 81$ & Baixa Grande, BA & Ipira, BA & 1 & 2 & 2 & 4 & 1 & 2 & 1 & 11 \\
\hline 2265 & $18^{\circ} 8^{\prime} \mathrm{S}$ & $43^{\circ} 33^{\prime} \mathrm{W}$ & - & Diamantina, MG & Diamantina, $\mathrm{MG}$ & 4 & 2 & 6 & 7 & 4 & 6 & 2 & 36 \\
\hline 2712 & $10^{\circ} 8^{\prime} \mathrm{S}$ & $45^{\circ} 13^{\prime} \mathrm{W}$ & $01 / 06 / 83$ & Corrente, PI & S. Gonç. Gurgueia, PI & 6 & 3 & 4 & 7 & 3 & 6 & 2 & 34 \\
\hline 2713 & $10^{\circ} 49^{\prime} \mathrm{S}$ & $41^{\circ} 12^{\prime} \mathrm{W}$ & $01 / 06 / 83$ & Jacobina, BA & Ourolândia, BA & 1 & 5 & 4 & 3 & 1 & 1 & 2 & 1 \\
\hline 2714 & $10^{\circ} 22^{\prime} \mathrm{S}$ & $41^{\circ} 19^{\prime} \mathrm{W}$ & $01 / 06 / 83$ & Alagoinhas, BA & Umburanas, BA & 1 & 5 & 7 & 7 & 1 & 1 & 1 & 2 \\
\hline 2715 & $11^{\circ} 9^{\prime} \mathrm{S}$ & $41^{\circ} 20^{\prime} \mathrm{W}$ & $01 / 06 / 83$ & Morro d Chapéu, BA & Morro do Chapéu, BA & 1 & 5 & 5 & 2 & 2 & 1 & 1 & 3 \\
\hline 2716 & $12^{\circ} 47^{\prime} \mathrm{S}$ & $43^{\circ} 13^{\prime} \mathrm{W}$ & $01 / 06 / 83$ & Paratinga, BA & Paratinga, BA & 1 & 5 & 3 & 5 & 2 & 3 & 1 & 17 \\
\hline 2717 & $14^{\circ} 3^{\prime} \mathrm{S}$ & $42^{\circ} 32^{\prime} \mathrm{W}$ & $01 / 06 / 83$ & Igopora, BA & Caeté, BA & 1 & 5 & 6 & 3 & 2 & 3 & 4 & 16 \\
\hline 2719 & $12^{\circ} 34^{\prime} \mathrm{S}$ & $42^{\circ} 18^{\prime} \mathrm{W}$ & $01 / 06 / 83$ & Br.242, BA & Ibitiara, BA & 1 & 5 & 7 & 7 & 2 & 2 & 1 & 14 \\
\hline 2720 & $12^{\circ} 12^{\prime} \mathrm{S}$ & $43^{\circ} 30^{\prime} \mathrm{W}$ & $01 / 06 / 83$ & Ibotirama, BA & Muquém S. Francis., BA & 1 & 5 & 4 & 3 & 2 & 4 & 1 & 25 \\
\hline 2721 & $12^{\circ} 7^{\prime} \mathrm{S}$ & $44^{\circ} 2^{\prime} \mathrm{W}$ & $01 / 06 / 83$ & Ibotirama, BA & Wanderley, BA & 1 & 5 & 5 & 7 & 3 & 3 & 2 & 19 \\
\hline $2777^{(2)}$ & $15^{\circ} 38^{\prime} \mathrm{S}$ & $47^{\circ} 34^{\prime} \mathrm{W}$ & $14 / 06 / 77$ & Brasília, DF & Brasília, DF & 2 & 4 & 7 & 3 & 6 & 6 & 1 & 39 \\
\hline 2779 & $14^{\circ} 52^{\prime} \mathrm{S}$ & $46^{\circ} 24^{\prime} \mathrm{W}$ & $27 / 09 / 78$ & Alvorada do Norte, GO & Formoso, $\mathrm{MG}$ & 4 & 5 & 5 & 3 & 6 & 6 & 2 & 38 \\
\hline 2780 & $14^{\circ} 35^{\prime} \mathrm{S}$ & $46^{\circ} \quad 9^{\prime} \mathrm{W}$ & $27 / 09 / 78$ & Alvorada do Norte, GO & Damianópolis, GO & 3 & 1 & 5 & 6 & 5 & 6 & 5 & 38 \\
\hline 2782 & $12^{\circ} 18^{\prime} \mathrm{S}$ & $42^{\circ} 54^{\prime} \mathrm{W}$ & $05 / 10 / 78$ & Ibotirama, BA & Oliveira dos Brejinhos, BA & 1 & 5 & 4 & 3 & 2 & 2 & 1 & 13 \\
\hline 2783 & $12^{\circ} 27^{\prime} \mathrm{S}$ & $42^{\circ} 11^{\prime} \mathrm{W}$ & $29 / 09 / 78$ & Seabra, BA & Ibitiara, BA & 1 & 5 & 7 & 3 & 2 & 1 & 7 & 4 \\
\hline 2784 & $12^{\circ} 3^{\prime} \mathrm{S}$ & $44^{\circ} 19^{\prime} \mathrm{W}$ & $28 / 09 / 78$ & Barreiras, BA & Cotegipe, BA & 1 & 5 & 4 & 8 & 3 & 6 & 2 & 35 \\
\hline $2790^{(2)}$ & $12^{\circ} 26^{\prime} \mathrm{S}$ & $40^{\circ} 49^{\prime} \mathrm{W}$ & $04 / 10 / 78$ & Itaberaba, BA & Lajedinho, BA & 1 & 2 & 4 & 8 & 2 & 4 & 1 & 26 \\
\hline $2792^{(2)}$ & $12^{\circ} 24^{\prime} \mathrm{S}$ & $41^{\circ} 42^{\prime} \mathrm{W}$ & $29 / 09 / 78$ & Seabra, BA & Seabra, BA & 1 & 2 & 6 & 3 & 2 & 6 & 3 & 31 \\
\hline $2794^{(2)}$ & $18^{\circ} 8^{\prime} \mathrm{S}$ & $43^{\circ} 33^{\prime} \mathrm{W}$ & $03 / 07 / 80$ & Mendanha, MG & Diamantina, $\mathrm{MG}$ & 4 & 2 & 6 & 7 & 4 & 6 & 1 & 36 \\
\hline 2795 & $17^{\circ} 11^{\prime} \mathrm{S}$ & $43^{\circ} 33^{\prime} \mathrm{W}$ & $07 / 06 / 79$ & Trebol, MG & Bocaiúva, MG & 4 & 2 & 6 & 7 & 3 & 6 & 1 & 34 \\
\hline
\end{tabular}

(1)E- Estado: 1, BA; 2, DF; 3, GO; 4, MG; 5, PA; 6, PI; 7, TO; B- Bacia: 1, Araguaia, TO; 2, Atlântico Leste; 3, Atlântico N- NE; 4, PR- Paraguai; 5, São Francisco; A- Altitude: 1, 1 a 165 m; 2, 166 a 335 m; 3, 336 a 506 m; 4, 507 a 668 m; 5, 669 a 825 m; 6, 826 a 1025 m; 7, 1.026 a 1.298 m; P- Pluviometria (média anual): 1, 550 a $700 \mathrm{~mm}$; 2, 700 a $850 \mathrm{~mm}$; 3, 850 a $1.000 \mathrm{~mm}$; 4, 1.000 a $1.150 \mathrm{~mm} ; 5,1.150$ a $1.300 \mathrm{~mm}$; $6,1.300$ a $1.450 \mathrm{~mm} ; 7,1.600$ a $1.750 \mathrm{~mm} ; 8,1.750$ a $1.900 \mathrm{~mm}$; 9 , até $2.870 \mathrm{~mm}$; S- Tipo de solo: 1, Brunizens; 2, Cambissolos; 3, Latossolos; 4, Planossolos; 5, Solos Aluviais; 6, Solos Arenoquartzosos Profundos; 7, Solos Litólicos; 8, Solos Podzólicos; V- Vegetação - Grupo: 1, Áreas de Tensão Ecológica (contatos entre tipos de vegetação); 2, Estepe; 3, Floresta Estacional Decidual (Mata Caducifolia); 4, Floresta Estacional Semidecidual (Mata Semicaducifolia); 5, Floresta Ombrófila Densa; 6, Savana; G- Grupos Genotípicos obtidos pela análise de dispersão; C- Agrupamento dos acessos de acordo com a similaridade ambiental dos locais de coleta. ${ }^{(2)}$ Caracterizados agronomicamente por Schultze-Kraft (1984). ${ }^{(3)}$ Identificado posteriormente como Stylosanthes capitata. 
mo acesso, realizou-se também a extração de DNA genômico. Para tanto, foram utilizadas 11 plantas de cada um dos acessos, CPAC 1033, CPAC 1043, CPAC 1192 e CPAC 2251, selecionados com base na maior divergência genética em relação aos demais acessos. Na extração do DNA de cada material genético, foram utilizadas folhas provenientes de pelo menos três plantas, extraindo-se, em conjunto, o DNA (bulk).

A quantidade do DNA foi estimada por espectrofotometria a $260 \mathrm{~nm}$. A relação A260/A280 foi utilizada para avaliar a pureza do DNA. Bandas de DNA genômico total separadas por eletroforese em gel de agarose $0,8 \%(\mathrm{p} / \mathrm{v})$ foram usadas como indicadoras da integridade do DNA extraído.

A fim de avaliar a diversidade genética dos acessos, amostras de DNA de cada material genético foram amplificadas via PCR (Reação em cadeia da polimerase) para a obtenção de marcadores RAPD. As reações de amplificação foram feitas em um volume total de $13 \mu \mathrm{L}$, contendo Tris-HCl (10 mM, pH 8,3), $\mathrm{KCl}(50 \mathrm{mM}), \mathrm{MgCl}_{2}$ (3 mM, $100 \mu \mathrm{M}$ ) de cada um dos desoxirribonucleotídios (dATP, dTTP, dGTP e dCTP), 0,4 $\mu \mathrm{M}$ de um primer decâmero (Operon Technologies Inc.), uma unidade da enzima Taq polimerase e, aproximadamente, 15 ng de DNA. Foram testados 22 primers dos quais 15 foram selecionados por apresentarem padrões de bandas mais consistentes: OPD1, OPD3, OPD11, OPE1, OPE2, OPE6, OPE11, OPE14, OPF3, OPF4, OPF7, OPF8, OPF9, OPF12 e OPF14.

As amplificações foram efetuadas em termociclador, programado para 40 ciclos, cada um constituído pela seguinte seqüência: 15 segundos a $94^{\circ} \mathrm{C}, 30$ segundos a $35^{\circ} \mathrm{C}$ e 90 segundos a $72^{\circ} \mathrm{C}$. Após os 40 ciclos, foi realizada uma etapa de extensão de 6 minutos a $72^{\circ} \mathrm{C}$ e redução para $4^{\circ} \mathrm{C}$. Após a amplificação, foram adicionados, a cada amostra, $3 \mu \mathrm{L}$ da mistura de azul de bromofenol $(0,25 \% \mathrm{p} / \mathrm{v})$, glicerol $(60 \% \mathrm{v} / \mathrm{v})$ em água. $\mathrm{O}$ volume total de cada amostra foi aplicado em gel de agarose (1,2\%), corado com brometo de etídio, submerso em tampão TBE (Tris-Borato 90 mM, EDTA 1 mM). A separação eletroforética foi de quatro horas, a 90 volts. Ao término da corrida, os géis foram fotografados sob luz ultravioleta.

Além da diversidade genética dos 88 acessos de Stylosanhtes spp., foi avaliada a variabilidade genética dentro dos acessos, CPAC 1033, CPAC 1043, CPAC 1192 e CPAC 2251. Onze plantas de cada um dos acessos foram analisadas utilizando-se os primers OPD3, OPE1, OPE11, OPE14, OPF3, OPF4 OPF12 e
OPF14 para obtenção dos marcadores RAPD. As amplificações foram efetuadas da mesma forma que na obtenção de marcadores de RAPD para a diversidade entre os acessos.

Os marcadores RAPD gerados foram convertidos em uma matriz de dados binários, a partir da qual foram estimadas as distâncias genéticas entre os diferentes acessos, com base no complemento do coeficiente de similaridade de Nei \& Li, utilizando-se o Programa Genes (Cruz, 1997). A matriz de distâncias genéticas foi utilizada para realizar a análise de diversidade genética por meio de dendrograma e dispersão gráfica baseada nas coordenadas principais. Utilizou-se como critério de agrupamento dos acessos o método UPGMA (Critério de agrupamento não-viesado baseado na média aritmética), com o auxílio do sistema SAS (SAS Institute, 1990).

\section{Resultados e Discussão}

Os descritores ecológicos de cada acesso foram obtidos com base nas características ecogeográficas dos pontos de coleta. A partir das informações geradas pelos mapas de estados e municípios e de estradas de rodagem, foi feita a análise das rotas das expedições de coleta dos acessos de S. macrocephala. Observou-se que os acessos foram coletados, em sua maioria, ao longo das rodovias. Outra informação gerada pelo mapa de estados e municípios foi que, em $66 \%$ dos casos, o nome do município de coleta contido nos dados de passaporte foi diferente daquele gerado pelo SIG. Essas diferenças nos nomes dos municípios ocorreram em virtude de desatualização cadastral, surgimento de novos municípios e erros de localização quando a coleta ocorreu muito próximo às divisas municipais.

As coordenadas geográficas do local de coleta do acesso CPAC 1636, em Belém, PA, levantaram suspeita quanto à sua verdadeira origem porque não existiam registros de coletas de $S$. macrocephala naquela região. Em virtude da incerteza quanto à origem do acesso, não foram registrados seus descritores ecológicos.

Uma vez confirmados os locais de coleta, outras informações ecogeográficas foram obtidas com base nos diferentes mapas digitais manipulados pelo SIG (Tabela 1). Verificou-se que, dos 86 acessos, 53 tiveram origem no Estado da Bahia, 21 em Minas Gerais, sete em Goiás, três no Distrito Federal, um acesso em Tocantins e um no Piauí. Quanto à distribuição dos acessos nas bacias hidrográficas, 45 acessos foram coletados na 
Bacia do Atlântico Leste, 29 na Bacia do São Francisco, oito na Bacia do Araguaia, quatro na Bacia do Paraná-Paraguai e um na Bacia do Atlântico Norte-Nordeste. Em relação à vegetação, as coletas foram realizadas em sete tipos distintos: 39 coletas foram realizadas no ambiente de cerrado (Grupo: Savana), 16 em áreas de Tensão Ecológica (Tabela 1). Os acessos foram coletados, predominantemente, em solos com baixa fertilidade, sendo $43 \mathrm{em}$ latossolo e $23 \mathrm{em}$ solos litólicos. Os outros acessos foram coletados em sete tipos de solos (Tabela 1). Os locais de coleta apresentaram altitudes variando de 1 a $1.298 \mathrm{~m}$ e a pluviometria anual média de 550 a $2.870 \mathrm{~mm}$ por ano.

Com base na similaridade ambiental do local de coleta, foram identificados 44 grupos de acessos. Por este critério ficaram agrupados, por exemplo, os acessos CPAC 2232 e CPAC 2251, coletados nos estados da Bahia e de Minas Gerais, respectivamente. Esses dois acessos foram obtidos de locais com altitudes na faixa de 669 a 825 m, vegetação do tipo Floresta Estacional Decidual em Latossolos e em locais com pluviometria anual média de 1.000 a 1.150 mm. Os 44 grupos de acessos definidos com base na similaridade ambiental do local de coleta sugerem a presença de acessos com diferentes capacidades adaptativas, sendo um indicativo da variabilidade genética da coleção analisada. Vários autores têm utilizado critérios ecogeográficos como indicativo da variabilidade genética de coleções de germoplasma (Chapman \& Barreto, 1996; Greene et al., 1999; Grenier et al., 2001; Guarino, et al., 2002). Tal variabilidade é essencial em programas de melhoramento genético.

A análise dos acessos foi baseada em 188 marcadores RAPD, gerados por 15 primers, perfazendo uma média de 12,5 marcas por primer. As distâncias genéticas entre os acessos variaram de 0,02 a 0,74. A análise de dispersão gráfica (Figura 1A) permitiu observar o isolamento da cv. Mineirão (out group) e do CPAC 1348, identificado posteriormente como S. capitata. Confusões na classificação das espécies $S$. capitata e S. macrocephala são relativamente comuns por causa de semelhanças botânicas compartilhadas por estas espécies (Schultzew-Kraft et al., 1984). Considerando-se apenas os 86 acessos de S. macrocephala, foram analisados 161 marcadores RAPD, perfazendo uma média de 10,7 marcadores por primer. Mesmo após a retirada dos out group, S. guianensis e S. capitata, observouse alta variabilidade genética dentro da coleção de 86 acessos de S. macrocephala, com distâncias dadas pela matriz de distâncias genéticas entre 0,023 e 0,42 (Figura 1 B).

Esta alta variabilidade intra-específica não foi observada em outras espécies estudadas por Kazan et al. (1993). Estes autores estudaram a diversidade genética
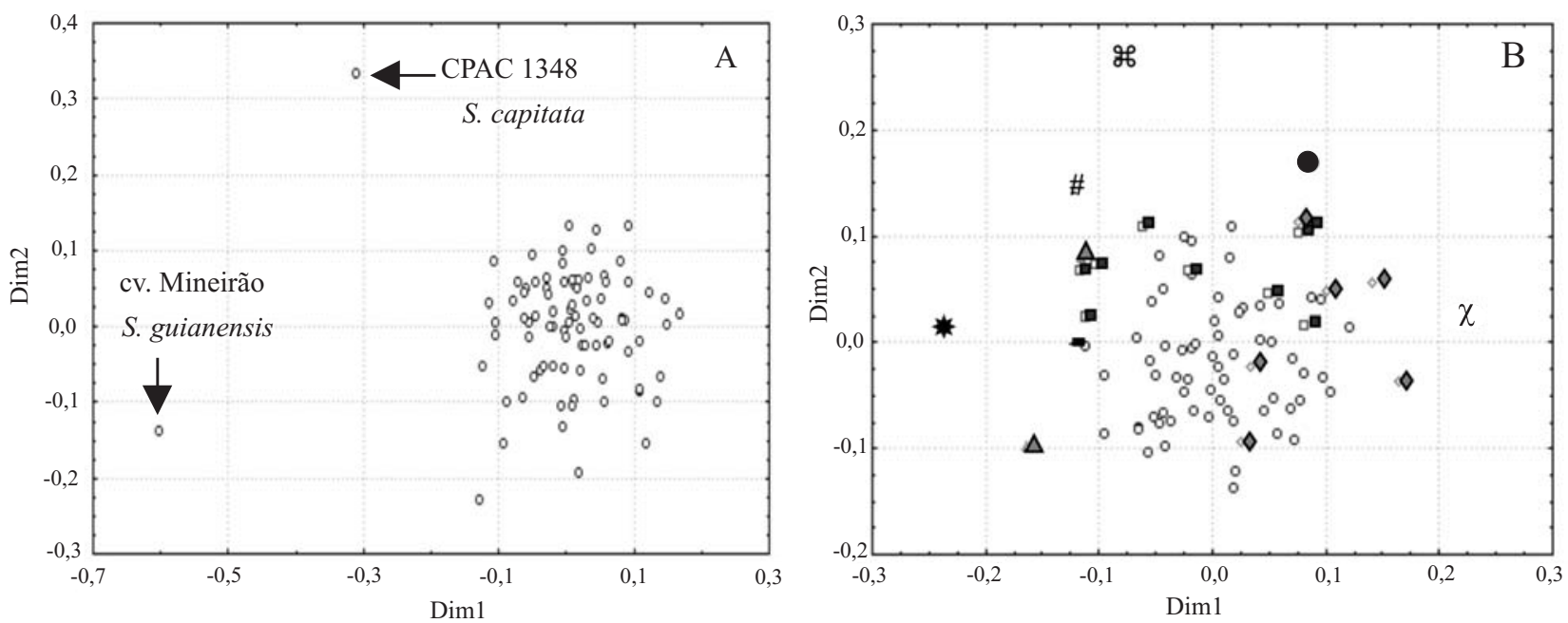

Figura 1. Dispersão gráfica dos acessos de Stylosanthes spp. com base na matriz de distâncias genéticas geradas por 176 marcadores RAPD. A análise de grupamento foi feita com base no critério do UPGMA (Critério de agrupamento não-viesado baseado na média aritmética), com o auxílio do sistema SAS. A: Dispersão dos 88 acessos. B: Dispersão e agrupamento dos 86 acessos de S. macrocephala, sendo: Grupo 1 (○); Grupo 2 ( $\square$ ); Grupo 3 (४); Grupo 4 (४); Grupo 5, CPAC1033 (H); Grupo 6,

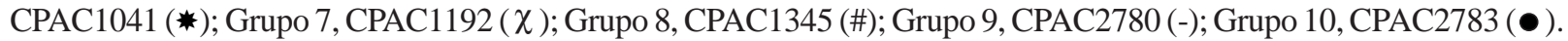


entre 20 cultivares e acessos das espécies, S. scabra, S. hamata, S. guianensis, S. humilis, utilizando marcadores moleculares do tipo RAPD, e encontraram alta variabilidade interespecífica e baixa variabilidade dentro da espécie. Stappen et al. (1998) obtiveram melhor discriminação dessa variabilidade genética em S. guianensis por meio de marcadores moleculares da região ITS1. Karia et al. (2002), baseados em marcadores morfológicos e agronômicos, observaram alta variabilidade intra-específica no estudo de 72 acessos de $S$. guianensis, 44 de $S$. capitata e 26 de S. scabra. A análise de agrupamento de cem acessos de S. scabra, coletados no Brasil, Colômbia e Venezuela, permitiu discriminar os acessos em cinco grupos genéticos, nos quais observou-se variabilidade intra-específica menor nos acessos brasileiros comparados aos dos outros dois países (Liu, 1997).

A análise de agrupamento, via dendrograma, dos 86 acessos de $S$. macrocephala permitiu a formação de dez agrupamentos, traçando-se uma linha de corte na distância de genética relativa de 0,45 (Figura 2): o grupo 1, com 63 acessos, o grupo 2, com 9 acessos, o grupo 3, com 6 acessos e o grupo 4, com 2 acessos. Seis grupos apresentaram apenas um acesso, indicando divergência genética entre eles. No grupo 1, existem vários subgrupos, com distâncias genéticas entre 0,023 e 0,243 . Os acessos mais próximos foram CPAC 1307 , CPAC 1308, CPAC 1309, CPAC 1310 e CPAC 1311, com distâncias entre 0,023 a 0,063 . Os acessos CPAC 1636, CPAC 1644, CPAC 2227, CPAC 1639 e CPAC 1640 também são similares com distâncias genéticas entre 0,035 e 0,099 .

Na avaliação da variabilidade genética dentro do acesso, baixas distâncias genéticas $(0,00$ a 0,06$)$ entre plantas do mesmo acesso foram observadas. Entretanto, foi possível observar a presença de uma planta do acesso CPAC 2251 diferente das demais, com distâncias genéticas variando entre 0,27 e 0,41. Este resultado é um forte indício de contaminação física de sementes ou de um produto de polinização cruzada. No acesso CPAC 1192, uma planta apresentou uma pequena distância genética, de 0,04, das demais plantas, sugerindo se tratar de um possível produto de segregação (Figura 3).

A baixa diversidade intra-acesso era esperada considerando que a reprodução da espécie é preferencialmente por autofecundação. Não existem estudos mostrando a taxa de cruzamento dentro da espécie S. macrocephala, mas em S. scabra foi verificada uma taxa de 2\% (Stace, 1984). Essa taxa de fecundação cruzada, entretanto, pode chegar a valores maiores, como os observados em $S$. guianensis, obtidos por Miles (1985).

A análise conjunta da diversidade genética e dos descritores ecológicos dos acessos de $S$. macrocephala mostrou que nos estados da Bahia e de Minas Gerais foram coletados acessos com alta variabilidade genética (Figura 4). Este resultado é condizente para uma região centro de origem da espécie (Schultze-Kraft et al., 1984).

No Estado da Bahia, coletou-se o maior número de acessos com diferenças genéticas e ecológicas, em decorrência do grande número de coletas realizadas neste Estado. Dos acessos coletados na Bahia, 25\% não pertencem ao grupo genético 1 . A região que forneceu o maior número de acessos distintos foi a do polígono Barreiras, Ourolândia, Tanhaçus e Caetitê. Esses acessos coletados nesta região foram alocados em 8 (grupos 2, 3, 4, 6, 7, 9 e 10) dos 10 grupos genéticos observados. Os acessos coletados em Minas Gerais também apresentaram alta diversidade genética, sendo $43 \%$ dos acessos coletados não pertencentes ao grupo 1 . As regiões de Corinto, Bocaiúvas, Diamantina e Lagoa Santa merecem destaque quanto à coleta de acessos com alta diversidade genética, pertencentes aos grupos 2, 3, 4 e 8. Essas regiões de Minas Gerais e da Bahia são interessantes para futuras coletas, de modo a maximizar a diversidade genética dos acessos coletados, o que é essencial em trabalhos de caracterização e de melhoramento genético. Observou-se baixo número de coletas realizadas nos estados de Tocantins e Piauí, regiões que poderão ser melhor exploradas para a obtenção de novos genótipos de S. macrocephala.

Houve tendência de regionalização da variabilidade genética com base nas bacias hidrográficas, 66,7\% dos acessos do grupo 2 foram coletados na Bacia do São Francisco e 66,7\% dos acessos do grupo 3 na Bacia Atlântico Leste. Os estudos da distribuição da variabilidade intra-específica de S. scabra (Liu,1997), S. humilis e S. viscosa (Sawkins et al., 2001) também indicaram tendência de regionalização da variabilidade quando grandes áreas foram analisadas. A altitude, a pluviometria, o tipo de solo e a vegetação não mostraram relação com a variabilidade genética.

Alguns acessos pertencentes a grupos genéticos distintos foram coletados em ecossistemas semelhantes. Os acessos CPAC 1191 (grupo 1) e CPAC 1192 (gru- 


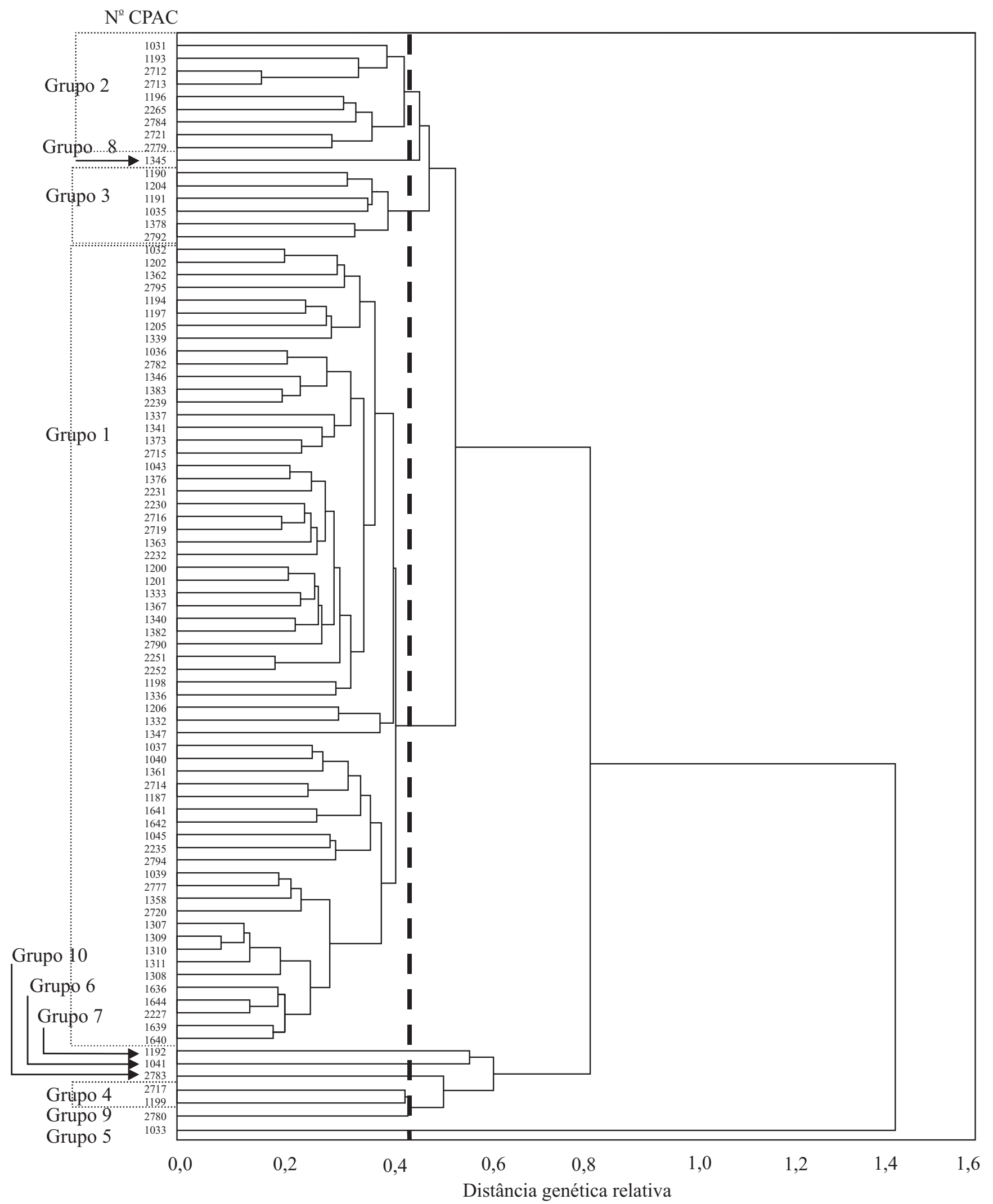

Figura 2. Análise de agrupamento de 86 acessos de Stylosanthes macrocephala baseada na matriz de distâncias genéticas calculadas com 161 marcadores RAPD. O critério de agrupamento foi o do UPGMA. 


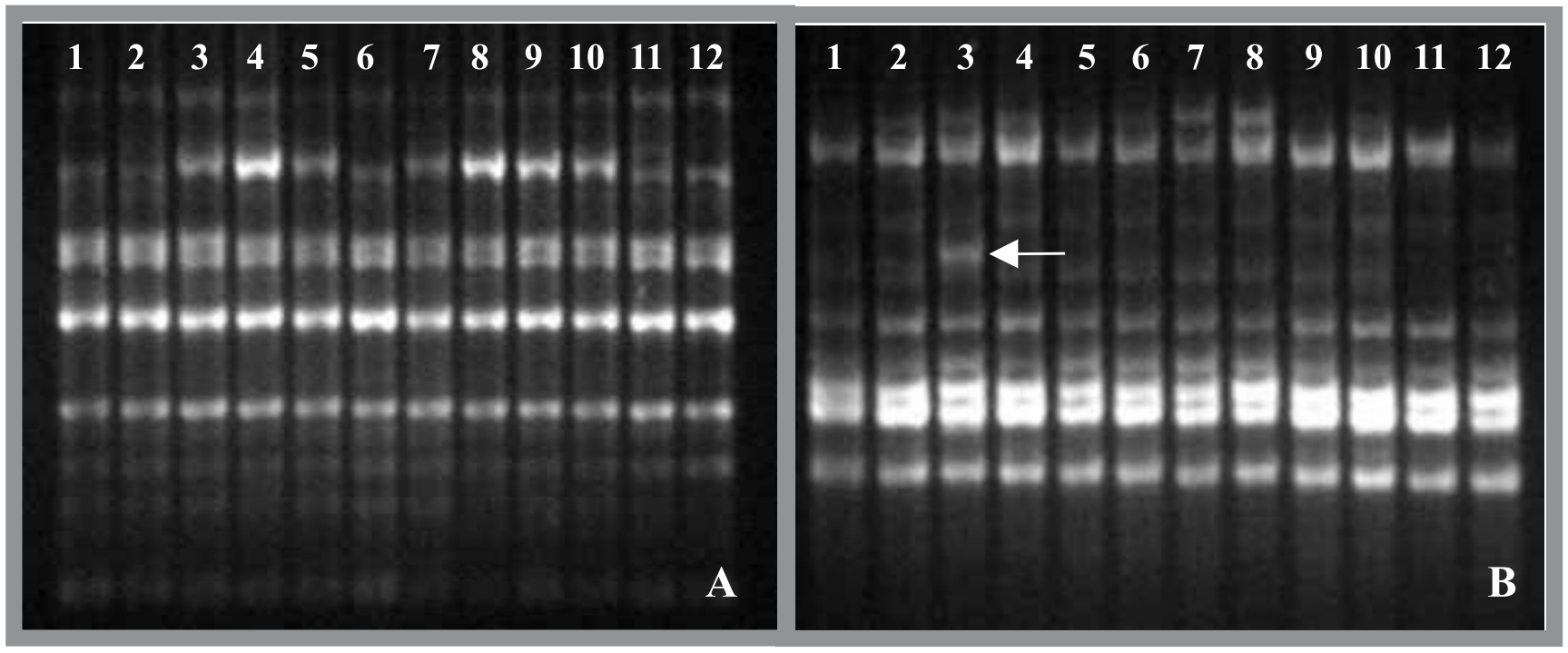

Figura 3. Produtos de amplificação de amostras de DNA genômico de 11 plantas do acesso CPAC 1192, gerados com a utilização do primer OPD-03 (A) e OPE-01 (B). A seta indica um polimorfismo verificado na planta 3 . A coluna 12 mostra os produtos de amplificação de um bulk de amostras de DNA do mesmo acesso.

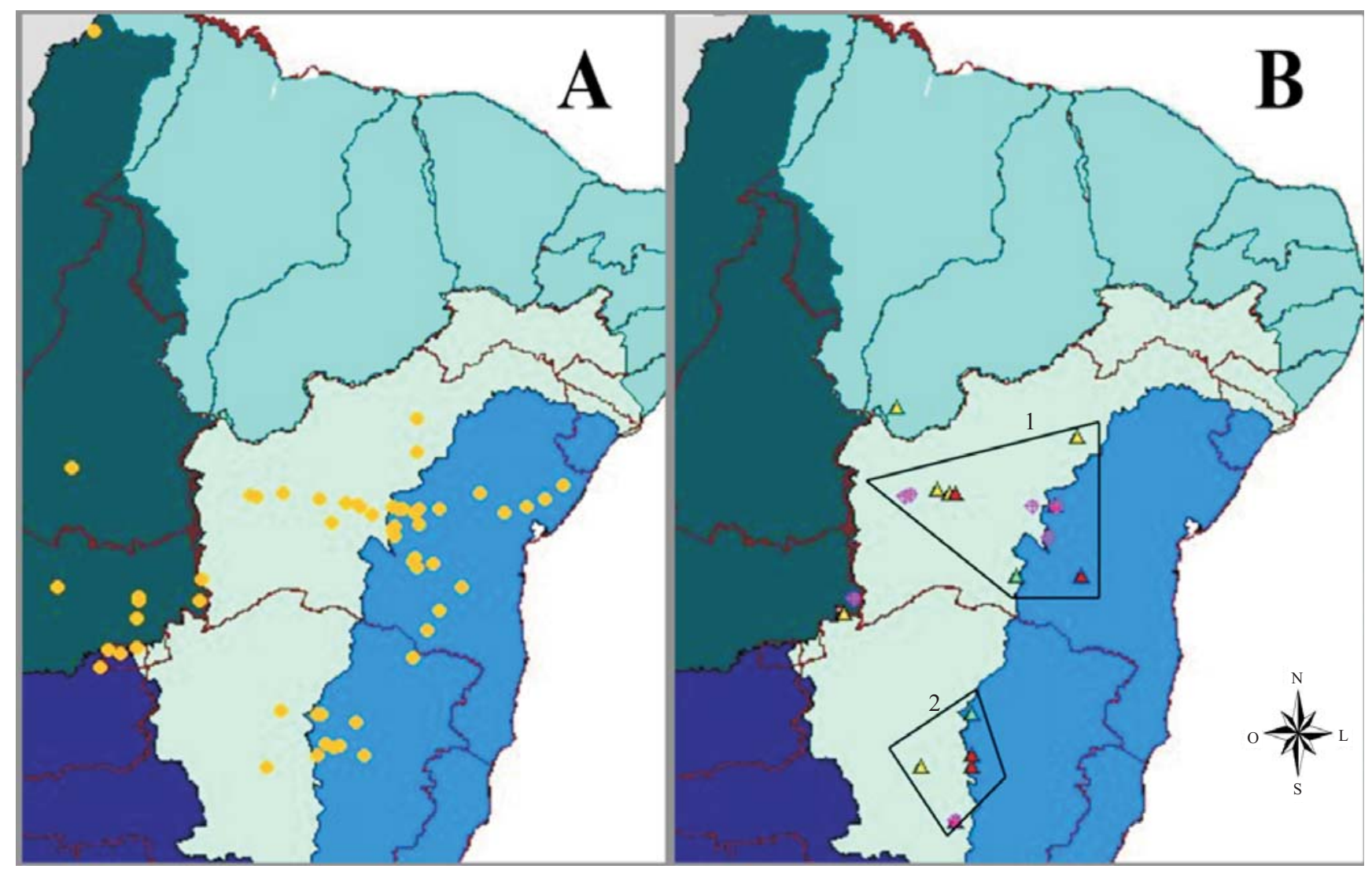

Figura 4. Distribuição geográfica dos acessos de $S$. macrocephala geneticamente próximos (A). Distribuição dos acessos mais divergentes geneticamente $(\mathrm{B})$. As áreas demarcadas (1 e 2) correspondem àquelas regiões onde foram coletados acessos com maior diversidade genética entre si. Grupo $1(\odot)$, Grupo $2(\Delta)$, Grupo $3(\Delta)$, Grupo $4(\Delta)$, acessos grupos 6 a $10(\oplus)$; $\square$ Estados Brasileiros; Bacias hidrográficas: $\square$ Bacia Araguaia - TO; $\square$ Atlântico Leste; $\square$ Atlântico N-NE; $\square$ Paraná Paraguai; $\square$ São Francisco. 
po 4), por exemplo, foram coletados no mesmo local em Lagoa Santa, MG, e os acessos CPAC 1040 (grupo 1) e CPAC 1041 (grupo 6) foram provenientes de Seabra, BA. De forma inversa, observou-se alta similaridade genética entre alguns acessos coletados em diferentes ecossistemas no Distrito Federal e Goiás, como os acessos CPAC 1307, CPAC 1309, CPAC 1310 e CPAC 1311, pertencentes ao grupo 1 (Figura 2).

A alta variabilidade genética entre os acessos de S. macrocephala mostrou a importância das coletas realizadas, entretanto, a presença de grupos com poucos representantes sugere diversidade genética ainda maior do que a presente na coleção estudada, indicando a possibilidade de ampliar a variabilidade genética em novas expedições.

\section{Conclusões}

1. Os marcadores RAPD permitem a diferenciação entre acessos de Stylosanthes macrocephala, evidenciando a alta variabilidade genética.

2. A diversidade genética entre os acessos de S. macrocephala mostra a importância desta coleção em futuros trabalhos de caracterização agronômica e de melhoramento genético.

3. O SIG permite atualizar e gerar novos descritores ecológicos para acessos de S. macrocephala analisados, cujas informações são úteis na identificação de suas características adaptativas.

4. A análise conjunta da diversidade genética e dos descritores ecológicos mostra tendência de regionalização da variabilidade genética por bacia hidrográfica.

\section{Referências}

ANDRADE, R.P.; KARIA, C.T. O uso de Stylosanthes em pastagens no Brasil. In: SIMPÓSIO DE FORRAGICULTURA E PASTAGEM, 1., 2000, Lavras. Temas em evidências. Lavras: UFLA, 2000. p.273-309.

ANDRADE, R.P.; KARIA, C.T.; RAMOS, A.K.B. Stylosanthes as a forage legume at its centre of diversity. In: CHAKRABORTY, S. (Ed.). High-yielding anthracnose-resistant Stylosanthes for agricultural systems. Canberra: Australian Centre for International Agricultural Research, 2004. p.37-50.

BERTOZO, M.R.; VALLS, J.F.M. Seed storage protein electrophoresis in Arachis pintoi and A. repens (Leguminosae) for evaluating genetc diversity. Genetic Resources and Crop Evolution, v.48, p.121-130, 2001.
BRASIL. Ministério das Minas e Energia. Secretaria Geral. Projeto Radam Brasil. Folha SD.22 Goiás: geologia, geomorfologia, pedologia, vegetação e uso potencial da terra. Rio de Janeiro, 1981. 640p.

CHAPMAN, S.H.; BARRETO, H.J. Using simulation models and spatial databases to improve the efficiency of plant breeding programs. In: COOPER, M.; HAMMER, G.L. (Ed.). Plant adaptation and crop improvement. Wallingford: CAB International, 1996. p.563-587.

CRUZ, C.D. Programa Genes: aplicativo computacional em genética e estatística. Viçosa: UFV, 1997. 442p.

EMBRAPA. Centro Nacional de Pesquisa de Gado de Corte. Recomendações para estabelecimento e utilização do Stylosanthes guianensis cv. Mineirão. Campo Grande: EmbrapaCNPGC, 1993. 6p. (Embrapa-CNPGC. Comunicado Técnico, 49). ESRI. ArcView GIS. Redlands, 1996.

FALEIRO, F.G.; FALEIRO, A.S.G.; CORDEIRO, M.C.R.; KARIA, C.T. Metodologia para operacionalizar a extração de DNA de espécies nativas do cerrado visando a análises moleculares. Planaltina: Embrapa Cerrados, 2003. 5p. (Embrapa Cerrados. Comunicado Técnico, 92).

FERREIRA, M.B.; COSTA, N.M.S. O gênero Stylosanthes Sw. no Brasil. Belo Horizonte: EPAMIG, 1979. 107p.

FERREIRA, M.E.; GRATTAPAGLIA, D. Introdução ao uso de marcadores moleculares em análise genética. 2.ed. Brasília: Embrapa-Cenargen, 1996. 220p. (Embrapa-Cenargen. Documentos, 20).

GREENE, S.L.; HART, T.C.; AFOONIN, A. Using geographic information to acquire wild crop germoplasm for ex situ collections: II. Post-collection analysis. Crop Science, v.39, p.843-849, 1999.

GRENIER, C.; BRAMEL-COX, P.J.; HAMON, O. Core collection of sorghum. I. Stratification based on eco-geografical data. Crop Science, v.41, p.234-240, 2001.

GUARINO, L.; JARVIS, A.; HIJMANS, R.J.; MAXTED, N. Geographic information systems (GIS) and the conservation and use of plant genetic resource. In: EGELS, J.M.M.; RAMATHA, R.A.O.V.; BROWN, A.H.D.; JACKSON, M.T. (Ed.). Managing plant genetic diversity. Wallingford: CABI Publishing, 2002. p.387404.

HARRISON, R.E.; LUBY, J.J.; FUNIER, G.R.; HANCOCK, J.F. Differences in the apportionment of molecular and morphological variation in North American strawberry and consequences for genetic resources management. Genetic Resources and Crop Evolution, v.47, p.647-657, 2000.

INTERNATIONAL TECHNICAL CONFERENCE ON PLANT GENETIC RESOURCE. Global plan of action for the conservation and sustainable utilization of plant genetic resources for food in agriculture: report. Leipzig, Germany: FAO, 1996.

JARVIS, A.; FERGUNSON, M.E.; WILLIAMS, D.E.; GUARINO, L.; JONES, P.G.; STALKER, H.T.; VALLS, J.F.M.; PITTMAN, R.N.; SIMPSON, C.E.; BRAMES, P. Biogeography of wild Arachis: assessing conservation status and setting future priorities. Crop Science, v.43, p.1100-1108, 2003. 
KARIA, C.T.; ANDRADE, R.P. de; CHARCHAR, M.J.d'A.; GOMES, A.C. Caracterização morfológica de acessos do gênero Stylosanthes no banco ativo de germoplasma da Embrapa Cerrados - coleção 1994/1995. Planaltina: Embrapa Cerrados, 2002. 24p. (Embrapa Cerrados. Boletim de Pesquisa e Desenvolvimento, 72).

KAZAN, K.; MANNERS, J.M.; CAMERON, D.F. Genetic variation in agronomically important species of Stylosanthes determined using random amplified polymorphic DNA mark. Theoretical and Applied Genetics, v.85, p.882-888, 1993.

LIU, C.J. Geographical distribution of genetic variation in Stylosanthes scabra revealed by RAPD analysis. Euphytica, v.98, p.21-27, 1997.

MILES, J.W. Evaluation of potential genetic marker traits and estimation of out crossing rate in Stylosanthes guianensis. Australian Journal of Agricultural Research, v.36, p.259-265, 1985.

SAS INSTITUTE (Cary, Estados Unidos). User guide version 6.04. $4^{\text {th }}$ ed. Cary, 1990.
SAWKINS, M.C.; MAASS, B.L.; PENGELLY, B.C.; NEWBURY, H.J.; FORD-LLOYD, B.V.; MAXTED, N.; SMITH, R. Geographical patterns of genetic variation in two species of Stylosanthes Sw. using amplified fragment length polymorphism. Molecular Ecology, v.10, p.1947-1958, 2001.

SCHULTZE-KRAFT, R.; COSTA, N.M.S.; FLORES, A. Stylosanthes macrocephala M. B. Ferr. et S. Costa: collection and preliminary agronomic evaluation of a new tropical pasture legume. Tropical Agriculture, v.61, p.229-240, 1984.

STACE, H.M. Breeding system in Stylosanthes. I. Observations of outcrossing in S. scabra at an alcohol dehydrogenase locus. Australia Journal of Agricultural Research, v.33, p.87-96, 1984.

STACE, H.M.; EDYE, L.A. (Ed.). The biology and agronomy of Stylosanthes. Sidney: Academic Press, 1984.

STAPPEN, J.V.; CAMPENHOUT, S.V.; LOPEZ S.G.; VOLCKAERT, G. Sequencing of the internal transcribed spacer region ITS1 as a molecular tool detecting variation in the Stylosanthes guianensis species complex. Theoretical Applied Genetics, v.96, p.869-877, 1998.

Recebido em 29 de abril de 2004 e aprovado em 10 de março de 2005 